\title{
Is Covid-19 lockdown related to an increase of accesses for seizures in the emergency department? An observational analysis of a paediatric cohort in the Southern Italy
}

\author{
Federica Palladino ${ }^{1}$ (D) Eugenio Merolla ${ }^{2} \cdot$ Marella Solimeno $^{2} \cdot$ Maria Fulvia de Leva $^{3} \cdot$ Selvaggia Lenta $^{4}$. \\ Onorina Di Mita ${ }^{4} \cdot$ Anna Bonadies $^{4} \cdot$ Pasquale Striano $^{5,6} \cdot$ Vincenzo Tipo $^{4} \cdot$ Antonio Varone $^{3}$
}

Received: 23 July 2020 / Accepted: 10 October 2020 / Published online: 23 October 2020

(C) The Author(s) 2020

\begin{abstract}
Background The World Health Organization (WHO) declared a global pandemic of Covid-19 on 11 March 2020. The lockdown caused a lifestyle changes: an increase in the use of mobile media devices (MMDs), sleep and psychiatric disorders, incorrect habits regarding food and physical activities.

We investigate prevalence of admission for seizures at our emergency department (ED), during Italian lockdown, comparing with that of the same period of the previous year (2019), and the relationship with some lifestyle changes.

Methods In this observational study, patients (4-14 years) with seizures that accessed at our ED, during Italian lockdown, were eligible. Non-epileptic events and febrile seizures were excluded. We describe two groups: patients with new-onset seizures and not. Moreover, a questionnaire concerning use of MMDs and sleep habits was administered.

Results Fifty-seven patients were included; median age 8.03 years. Considering only paediatric medical emergencies, the prevalence of accesses for seizures was $2.6 \%$ (CI 95\% 0.020-0.034), while the incidence was $0.94 \%$ (CI 95\% 0.006-0.0149). There was a statistically significant difference with prevalence of previous years, $\chi^{2} 102.21(p=0.0001)$. We also reported a difference in daily screen time (DST) $(p=0.001)$ and total sleep time (TST) $(p=0.045)$, in all population, between period preand during lockdown. A negative correlation between DST and seizures latency (Spearman's $\rho-0.426, p=0.038$ ) was found. In the two groups, the results were partially overlapping.

Conclusions During lockdown period, we assisted to an increase of accesses for seizures. It is conceivable that a sleep time change and/or higher MMD use could act as triggers for seizures.
\end{abstract}

Keywords Seizures $\cdot$ Lockdown $\cdot$ Mobile media devices $\cdot$ Sleep disorder $\cdot$ Children $\cdot$ COVID-19

Electronic supplementary material The online version of this article (https://doi.org/10.1007/s10072-020-04824-5) contains supplementary material, which is available to authorized users.

Federica Palladino

palladino.federica@gmail.com

1 Department of Women's and Children's Health and General and Specialized Surgery, University of Campania “Luigi Vanvitelli”, Via Luigi de Crecchio 2, 80138 Naples, Italy

2 Clinic of Child and Adolescent Neuropsychiatry, Department of Mental Health, Physical and Preventive Medicine, University of Campania "Luigi Vanvitelli”, Via Pansini 5, 80131 Naples, Italy
3 Pediatric Neurology, Department of Neuroscience, Santobono-Pausilipon Children's Hospital, Via Mario Fiore 6, 80129 Naples, Italy

4 Pediatric Emergency Department, Santobono-Pausilipon Children's Hospital, Via Mario Fiore 6, 80129 Naples, Italy

5 Pediatric Neurology and Muscular Diseases Unit, "IRCCS Istituto Giannina Gaslini", Genova, Italy

6 Department of Neurosciences, Rehabilitation, Ophthalmology, Genetics, Maternal and Child Health, University of Genova, Genova, Italy 


\section{Background}

The World Health Organization (WHO) declared a global pandemic of Covid 19 - the disease caused by Sars-Cov2on Wednesday 11 March 2020 (https://www.who.int/dg/ speeches/detail/who-director-general-s-opening-remarks-atthe-media-briefing-on-covid-19\%2D\%2D-11-march-2020), first reported in Wuhan (China) in December 2019 [1].

Since then, according to literature [2,3], we have witnessed a worldwide massive drop in emergency department (ED) paediatric admissions, partially due to both the higher prevalence of this disease in older age groups [4] and mildasymptomatic clinical course in children and adolescents [5].

This phenomenon is to relate, as well, to a reduction of other seasonal viral infections due to self-isolation and social distancing measures adopted by governments. Nevertheless, parental concerns about exposing their children to hospital environment delayed diagnosis of acute severe illnesses that needed to be treated [6].

The lockdown, isolation, contact restrictions and economic shutdown caused a change of the psychosocial environment. As a concomitant consequence, an increase of mental health disorders, in the paediatric population, was observed (anxiety, depression, panic attacks) [7].

Children and adolescents were placed under pressure by this new situation that included smart schooling, limited access to outdoor play spaces and sleep disorders [8]. As a consequence, the use of mobile media devices (MMDs), television, smartphones, tablets, computers and video consoles (PlayStation $^{\mathrm{TM}}, \mathrm{Xbox}^{\mathrm{TM}}$, Nintendo ${ }^{\mathrm{TM}}$ ) was increased.

We aimed to correlate lifestyle changes during the Covid19 pandemic with the occurrence of epileptic seizures in a paediatric population from Southern Italy. Moreover, we examined the correlation between seizures, increasing usage of MMDs and sleep disorders, during lockdown.

\section{Materials and methods}

This observational study involved patients attending ED of Santobono-Pausilipon Children's Hospital, one of the major paediatric hospitals in Southern Italy, during the Covid-19related lockdown in Italy (since the 9th of March 2020 up to 4th of May 2020). In this study, all patients entering the ED for seizures, from 4 to 14 years of age, were included. Non-epileptic events and febrile seizures were excluded. Our cohort was stratified into two groups, i.e. patients presenting with new-onset seizures and patients with a previous diagnosis of epilepsy.

Data including demographic characteristics (gender, age, family history for seizures), seizures semiology, previous diagnosis of epilepsy, pharmacological treatment and compliance to therapy before the seizure, admission at the neurological department or not, were collected. In addition, neurological exam, electroencephalographic (electroencephalography (EEG)) and neuro-radiological (computerized tomography $\mathrm{CT}$ or magnetic resonance imaging MRI) findings and diagnosis of epilepsy at discharge were reported. These data were collected analysing the ED database and medical records of the patients admitted to our Neurology Department.

Moreover, a brief questionnaire (appendix 1, English translation of the Italian administered version) was created to obtain data about the use of MMDs (daily screen time (DST); typology of device, television, smartphones, tablets, computers and video consoles and seizures latency from the last use of the device), sleep habits (total sleep time (TST), qualitative alterations of sleep) and how the usage varied in the lockdown period comparing it to the habitual mean usage. The questionnaire is composed of eleven questions, elaborated by adapting other existing and/or validated questionnaires [9-11]. It was administered via telephone to one of the child's parent; a verbal consent was obtained before the administration.

To compare the 2020 prevalence of admission for seizures at our ED with that of the previous year, we also reported the number of patient (4-14 years) attending our ED for seizures, from March up to April 2019. Furthermore, data including demographic characteristics (gender, age) and diagnosis of discharge were recorded.

Regarding discharge diagnosis, we reported the number of patients with final epilepsy diagnosis or only single seizures, and we described them according to the new classification of seizures and epilepsy of International League Against Epilepsy (ILAE) of 2017 [12].

\section{Statistical analysis}

Prevalence and incidence of admissions for seizures at our ED, during Italian lockdown period (9th March to 4th May 2020) and during the same period of 2019, were described. We compared prevalence and incidence of seizures at our ED of 2020 with those of 2019, respectively, using chi-squared test.

Continuous non-parametric variables are presented as median, IQR and range, whereas categorical variables are expressed as number and percentage. Wilcoxon test and Mann-Whitney U test were used to compare continuous non-parametric variables. Chi-squared test and Fisher's exact test were used for testing relationships between categorical variables. Spearman's correlation was used to evaluate the association between DST and age, DST and seizure latency; in case of a significant correlation, a simple linear regression was performed. Exclusively for patients with a discharge diagnosis of focal and generalized epilepsy, Binary logistic regression model was used to explore predictors for these diagnoses (DST, number of devices, TST). For all analyses, $p$ values $<0.05$ were considered statistically significant. IBM 
SPSS Statistics 22 Software for Windows was used for statistical analysis.

\section{Results}

From the 9th of March up to the 4th of May 2020, there were 3968 total accesses to our ED, 61 of them $(1.5 \%$, CI $95 \% 0.012-0.019)$ for critical events, 57 (1.4\%, CI 95\% $0.011-0.018)$ for seizures and 4 (0.1\%, CI 95\% 0.0005$0.0034)$ for non-epileptic paroxysmal events. Incidence of seizures was $0.5 \%$ (CI 95\% 0.003-0.008) (20/3931). Excluding surgical (829) and orthopaedic (553) accesses, and non-urgent (426) patients, the prevalence of seizures was $2.6 \%$ (57/2160) with CI 95\% 0.020-0.034. Incidence of seizures was $0.94 \%$ (CI 95\% 0.006-0.014)(20/2123), while the incidence of new epilepsy's diagnosis was $1.3 \%$ (CI 95\% 0.009-0.018)(28/2131). In the same period, last year, we recorded 16,923 admissions in ED, 40 (0.24\%) for critical events (1/40 patients had non-epileptic paroxysmal event). Prevalence of seizures was $0.23 \%$ (CI 95\% $0.001-$ 0.003 ) (39/16923), and the incidence was $0.08 \%$ (CI $95 \%$ 0.0004-0.001) (13/16886). Excluding surgical (2424) and orthopaedic (2319) accesses, and non-urgent (2397) patients, the prevalence and incidence of seizures were $0.4 \%$ (CI 95\% 0.003-0.005) (39/9783) and 0.13\% (CI 95\% 0.0008-0.0023) (13/9757), respectively. Incidence of new epilepsy's diagnosis was not reported because no reliable data were available. There was a statistically significant difference between the prevalence and incidence of seizure accesses between March and May 2020 and 2019: about prevalence $\chi^{2}=102.21(p=0.0001)$, while incidence $\chi^{2}$ $37.34(p=0.0001)$, in comparison to all accesses, whilst considering only the paediatric medical emergencies $\chi^{2}=111.36(p=0.0001)$ for prevalence and $\chi^{2}=41.18(p=$ $0.0001)$ for incidence.

There were not statistically significant differences about patients with new-onset seizures and known epilepsy. Data were reported in Table 1.

\section{Study Population}

Fifty-seven patients were enrolled in the study, 20 of them had new-onset seizures (35\%), whilst 37 (65\%) had known epilepsy or not new-onset seizures. Clinical and demographic data of both groups were summarised in Table 2 .

\section{Patients with new-onset seizures}

Of 20 patients, $9(45 \%)$ were male and $11(55 \%)$ female. The median age was 8 years (range 4.00-12.00) [IRQ 4.25-9.75]. Eight patients $(40 \%)$ had familiarity for epilepsy; one patient (5\%) for febrile seizures and $11(55 \%)$ had not familiarity for epilepsy and/or seizures. In 17 patients (85\%), neurological clinical examination was normal. Seventeen of 20 patients were hospitalized ( $85 \%)$.

At admission, 7 of 20 (35\%) patients had focal onset seizures (FOS), 9 (45\%) had generalized onset seizures (GOS) and $4(2 \%)$ had unknown onset seizures (UOS). Nineteen of 20 performed an EEG that showed a pathological pattern in 16 (80\%) patients: generalized epileptic anomalies in 3 patients and focal anomalies in 13 patients ( 9 temporal, 3 frontal and 1 multifocal). Only one patient $(5.3 \%), 8$ years old, was photosensitive.

Nineteen of 20 patients had undergone CT (16 patients) or MRI (3 patients) at least once in their life. In detail, for 2 patients, MRI showed a structural aetiology (one had a brain
Table 1 Admissions at emergency department. Categorical variables are expressed as a number and percentage

\begin{tabular}{llll}
\hline Admissions at emergency department & \multicolumn{2}{l}{ Study population } & \multirow{2}{*}{ P value } \\
\cline { 2 - 3 } & 2020 & 2019 & \\
\hline All accessess to the ED & 3968 & 16923 \\
o Surgical patients & 829 & 2424 \\
o Orthopedic patients & 553 & 2319 \\
o Non-urgent & 426 & 2397 \\
o Medical emergencies & 2160 & 9783 \\
o Seizures & 57 & 39 \\
$\quad$ New-onset seizures & 20 & 13 \\
$\quad$ Known epilepsy or not new-onset seizures & 37 & 26 & 0.8589 \\
o Non-epileptic events & 4 & 1 \\
Prevalence of seizures & $2.6 \%$ & $0.23 \%$ \\
Incidence of seizures & $0.94 \%$ & $0.13 \%$ \\
Incidence of new epilepsy's diagnosis & $12.96 \%$ & - & 0.00001 \\
\hline
\end{tabular}


tumour and the other had a malformation of cortical development, polymicrogyria).

Discharge diagnoses were epilepsy for 17 of 20 patients (85\%): 11 (64.7\%) were focal epilepsy (FE); 4 (23.5\%) were generalized epilepsy (GE); 1 (5.9\%) were combined focal and generalized epilepsy (CFGE); and 1 (5.9\%) were unknown epilepsy (UE). On the other hand, 2 of 20 patients (15\%) were diagnosed with seizures onset type: 1 (33.3\%) had focal onset seizure (FOS), and $2(66.7 \%)$ had generalized onset seizure (GOS).

Regarding epilepsy aetiology, we reported 2 patients with structural aetiology (1 tumour, unknown histology) and 1 with malformation of cortical development (polymicrogyria). Two patients had childhood epilepsy with centro-temporal spikes.

\section{Patients with known epilepsy or not new-onset seizures}

Of 37 patients, 16 (43.2\%) were male and 21 (56.8\%) female. The median age was 8 years (range 4.00-14.00) [IRQ 6.0012.00]. Eleven patients (30\%) had familiarity for epilepsy and 4 patients (11\%) for febrile seizures, and $22(59 \%)$ had not familiarity for epilepsy and/or seizures. In 18 patients $(48.6 \%)$, neurological clinical examination was normal. Twenty of 37 patients were hospitalized (54\%).

At admission, 24 of 37 patients (64.9\%) had known epilepsy: $14(58.3 \%)$ were FE, 7 (29.2\%) were GE and 3 (12.5\%) were UE. In addition, 13 of 37 patients $(35.1 \%)$ had not known epilepsy: 4 (31\%) had FOS, 3 (23\%) had GOS and 6 $(46 \%)$ had unknown onset seizures (UOS).

Thirty-three of 37 patients performed EEG that showed a pathological pattern in 27 (73\%) patients: generalized epileptic anomalies in 7 patients and focal anomalies in 13 patients (11 temporal, 5 occipital, 1 frontal, 2 multifocal and 1 hemispheric). Only one patient (3.7\%), 9 years old, was photosensitive, with photoparoxysmal response (PPR), manifested by intermittent photic stimulation (IPS).

Thirty-one of 37 patients had undergone CT (11 patients) or MRI (20 patients) at least once in their life. In detail, for 11 patients, MRI (9) and CT (2) showed a structural aetiology: 7 had hypoxic-ischemic syndrome; 2 had a brain tumour (one dysembryoplastic neuroepithelial tumour (DNET), one pilocytic astrocytoma diffuse) and one patient poroencephalic cyst of frontal lobe. Finally, one patient had structural anomalies related to his immune aetiology (Rasmussen's syndrome).

Discharge diagnoses were epilepsy for 35 of 37 patients (94.6\%): 19 (54.3\%) were FE; $11(31.4 \%)$ were GE; 2 $(5.7 \%)$ were combined focal and generalized epilepsy (CFGE) and 3 (8.6\%) were unknown epilepsy (UE). On the other hand, 2 of 37 patients $(5.4 \%)$ had unknown onset seizures.
Regarding epilepsy aetiology, we reported 11 patients with structural aetiology (7 patiens with hypoxic-ischemic syndrome, 2 patients with brain tumour, DNET and PA diffuse, one with poroencephalic cyst, one patient with immune aetiology, Rasmussen's syndrome). Three patients had a genetic aetiology; they were carrier of mutation in CACNA1A, CUL48 and WDR45 genes. Three patients had childhood epilepsy with centro-temporal spikes.

About patients of previous year, available data were reported in Table 2. Aetiologies of diagnosed epilepsy in all patients were reported in Table 3.

Nineteen patients were taking antiepileptic drugs, 14 of them $(73.7 \%)$ had declared a good compliance to the therapy.

\section{Questionnaire results}

Of the 57 enrolled patients, 45 were contacted by phone: 37 of them reported difference in the number of hours of exposure to the devices.

Sixteen of 45 patients (35.5\%) had new-onset seizures, while 29 of 45 patients (64.4\%) had known epilepsy or not new-onset seizures. In the two different groups, 15 (93.7\%) and $27(93.1 \%)$ patients, respectively, confirmed increased use of MMDs during lockdown. Five patients with new onset seizures and 6 with known epilepsy or not new-onset seizures experienced a seizure while using MMDs.

Twenty-one contacted patients (46.6\%) reported difference in sleep duration, 6 of them (28.6\%) had new-onset seizures. Twenty-three patients (51.1\%) referred poor sleep quality, 10 $(43.4 \%)$ of them had new-onset seizure.

In all our population, there was a statistically significant difference in DST $(p=0.001)$ and TST $(p=0.045)$, between period pre- and during lockdown. The median seizure latency from the last use of the device was 3.0 hours (0-24.0) [IQR 08.0]. The results were also comparable in the two separate groups. Moreover, only the difference between TST was not significant. Data were reported in Table 4.

We showed a correlation between DST and age at admission in ED ( Spearman's $\rho 0.522, p=0.001$ ) in all included patients. In detail, we confirmed this correlation both in patients with new-onset seizures (Spearman's $\rho$ 0.573, $p=$ 0.025 ) and in patients with known epilepsy (Spearman's $\rho$ $0.554, p=0.007)$.

Considering only patients with a diagnosis of FE and GE, we reported a negative correlation between DST and seizure latency (Spearman's $\rho 0.426, p=0.038$ ). A simple linear regression was calculated to predict interval of time since the last usage based on DST. A significant regression equation was found $(\mathrm{F}(1.22)=$ $6.219, p=0.021$ ), with a $\mathrm{R}^{2}$ of 0.220 . Seizure latency predicted is 10.881-0.861 (DST) hours. Seizure latency decreased 0.861 for each hours of DST. There was no correlation between TST and interval of time since the last usage $(p=0.387)$. We did not 
Table 2 Demographic and clinical characteristics of two groups: patients with new-onset seizures and patients with known epilepsy and not new-onset seizures, of 2020 and 2019 year. Categorical variables are expressed as a number and percentage. Continuous nonparametric variables are reported as the median, range and interquartile [IQR]

\begin{tabular}{|c|c|c|}
\hline Demographic and clinical characteristics & 2020 & 2019 \\
\hline \multicolumn{3}{|l|}{ Patients with new-onset seizures } \\
\hline $\mathrm{N}$ of patients & 20 & 13 \\
\hline Gender (male) & $9(45 \%)$ & $8(61.5 \%)$ \\
\hline Age (years) & $8(4-12)[4.25-9.75]$ & $6(4-10)[5-8]$ \\
\hline \multicolumn{3}{|l|}{ Familiarity for seizures } \\
\hline None & $11(55 \%)$ & \multirow[t]{3}{*}{ n.a. } \\
\hline Epilepsy & $8(40 \%)$ & \\
\hline Febrile seizures & $1(5 \%)$ & \\
\hline Hospitalised patients & $17(85 \%)$ & $3(23 \%)$ \\
\hline \multicolumn{3}{|l|}{ Admission diagnosis } \\
\hline Seizures onset & 20 & 13 \\
\hline Focal & $7(35 \%)$ & - \\
\hline Generalized & $9(45 \%)$ & $1(7.7 \%)$ \\
\hline Unknown & $4(2 \%)$ & $12(92.3 \%)$ \\
\hline \multicolumn{3}{|l|}{ Discharge diagnosis } \\
\hline Epilepsy & $17(85 \%)$ & $3(23 \%)$ \\
\hline Focal & $11(64.7 \%)$ & $2(66.7)$ \\
\hline Generalized & $4(23.5 \%)$ & $1(33.3 \%)$ \\
\hline Combined focal and generalized & $1(5.9 \%)$ & - \\
\hline Unknown & $1(5.9 \%)$ & - \\
\hline Seizures onset & $3(15 \%)$ & $10(77 \%)$ \\
\hline Focal & $1(33.3 \%)$ & $1(10 \%)$ \\
\hline Generalized & $2(66.7 \%)$ & - \\
\hline Unknown & - & $9(90 \%)$ \\
\hline \multicolumn{3}{|c|}{ Patients with known epilepsy and not new-onset seizures } \\
\hline $\mathrm{N}$ of patients & $37(65 \%)$ & $26(66.7 \%)$ \\
\hline Gender (male) & $16(43.2 \%)$ & $16(61.5 \%)$ \\
\hline Age (years) & $8(4-14)[6-12]$ & $9.5(5-13)[6.23-12]$ \\
\hline \multicolumn{3}{|l|}{ Familiarity } \\
\hline None & $22(59 \%)$ & \multirow[t]{3}{*}{ n.a. } \\
\hline Epilepsy & $11(30 \%)$ & \\
\hline Febrile seizures & $4(11 \%)$ & \\
\hline Hospitalised patients & $20(54 \%)$ & $3(11.5 \%)$ \\
\hline \multicolumn{3}{|l|}{ Admission diagnosis } \\
\hline Seizures onset & 13 & 8 \\
\hline Focal & $4(31 \%)$ & - \\
\hline Generalized & $3(23 \%)$ & - \\
\hline Unknown & $6(46 \%)$ & 8 \\
\hline Epilepsy & 24 & 18 \\
\hline Focal & $14(58.3 \%)$ & $15(83.3 \%)$ \\
\hline Generalized & $7(29.2 \%)$ & $3(16.7 \%)$ \\
\hline Combined focal and generaized & - & - \\
\hline Unknown & $3(12.5 \%)$ & - \\
\hline \multicolumn{3}{|l|}{ Discharge diagnosis } \\
\hline Epilepsy & 35 & 21 \\
\hline Focal & $19(54.3 \%)$ & $17(81 \%)$ \\
\hline Generalized & $11(31.4 \%)$ & $3(14.3 \%)$ \\
\hline Combined focal and generaized & $2(5.7 \%)$ & - \\
\hline Unknown & $3(8.6 \%)$ & $1(4.7 \%)$ \\
\hline Seizures onset & 2 & 5 \\
\hline Focal & - & - \\
\hline Generalized & - & . \\
\hline Unknown & 2 & 5 \\
\hline
\end{tabular}

confirm these results analysing data in two separated groups, patients with new-onset seizure [correlation between DST and seizure latency ( $p=0.384$ ), correlation between TST and seizure latency $(\mathrm{p}=0.530)]$ and patients with known epilepsy $(\mathrm{p}=0.244$ and $p=0.273$, respectively).

Seven patients reported the use of one device, 18 patients of two different devices, 13 patients of three, 3 patients of four, 2 patients reported no usage of devices and other 2 patients did not answer this question. There was no difference between the usage of two or more devices and the diagnosis of FE and GE ( $p=$ 0.716), neither between the usage of two or more devices and a newly seizure onset $(\mathrm{p}=0.821)$. Predictors for diagnosis of a FE and GE were investigated: no correlation with DST $p=0.679$, [OR 1.052 (CI 95\% 0.826-1.341)], neither regarding TST $p=$ 
Table 3 Epilepsy diagnosis and aetiologies in all population.

\begin{tabular}{lllll}
\hline Aetiologies & FE & GE & CFGE & UE \\
\hline Structural & 9 & - & 3 & - \\
$\quad$ Hypoxic-ischemic injury & 6 & - & 1 & - \\
Tumor & 2 & - & 1 & - \\
Malformations of cortical development & - & - & 1 & - \\
Porencephalic cyst & 1 & - & - & - \\
Genetic & 1 & 2 & - & - \\
Immune & 1 & - & - & - \\
Infectious & - & - & - & - \\
Metabolic & - & - & - & - \\
Unknown & $20 *$ & 13 & - & 3 \\
Total & 31 & 15 & 3 & 3 \\
\hline
\end{tabular}

$F E$ focal epilepsy, $G E$ generalized epilepsy, $C F G E$ combined focal and generalized epilepsy, $U E$ unknown epilepsy

*5 of them with Childhood epilepsy with centrotemporal spikes.

Table 4 Results of the questionnaire in all contacted patients (45), in patients with new-onset seizures, in patient with known epilepsy or not new-onset seizures.

Daily screen time (DST) and

p value total sleep time (TST)

\begin{tabular}{|c|c|c|}
\hline \multicolumn{3}{|l|}{ All population } \\
\hline \multicolumn{3}{|c|}{ Daily screen time (hours) } \\
\hline $\begin{array}{l}\text { Pre-lockdown } \\
\text { During lockdown }\end{array}$ & $\begin{array}{l}2.5(0.15-9.0)[\text { IQR } 1.5-3.0] \\
5.8(2.15-12)[\text { IQR 3.5-8.5] }\end{array}$ & $p 0.0001$ \\
\hline \multicolumn{3}{|c|}{ Total sleep time (hours) } \\
\hline $\begin{array}{l}\text { Pre-lockdown } \\
\text { During lockdown }\end{array}$ & $\begin{array}{l}9(7.0-13.5) \text { [IQR } 8.0-10.0] \\
8(6.5-12.0) \text { [IQR 7-10.12] }\end{array}$ & $p 0.117$ \\
\hline Seizure latency & $2.75(0-24)[$ IQR $0-9.0]$ & \\
\hline \multicolumn{3}{|c|}{ Patients with new-onset seizure } \\
\hline \multicolumn{3}{|c|}{ Daily screen time (hours) } \\
\hline $\begin{array}{l}\text { Pre-lockdown } \\
\text { During lockdown }\end{array}$ & $\begin{array}{l}2.5(1.0-5.0) \text { [IQR 1.5-3.0] } \\
7.5(2.5-12.5)[\text { IQR 6.0-10.0] }\end{array}$ & $p 0.0001$ \\
\hline \multicolumn{3}{|c|}{ Total sleep time (hours) } \\
\hline $\begin{array}{l}\text { Pre-lockdown } \\
\text { During lockdown }\end{array}$ & $\begin{array}{l}9.0(7.0-11.0)[\text { IQR 8.0-9.5] } \\
8.5(6.5-9.0)[\text { IQR 7.5-9.0] }\end{array}$ & $p 0.140$ \\
\hline Seizure latency & $5(0-10.0)[$ IQR $2.0-8.0]$ & \\
\hline \multicolumn{3}{|c|}{ Patients with known epilepsy or not new-onset seizure } \\
\hline \multicolumn{3}{|c|}{ Daily screen time (hours) } \\
\hline $\begin{array}{l}\text { Pre-lockdown } \\
\text { During lockdown }\end{array}$ & $\begin{array}{l}2.5(1.0-5.0)[\text { IQR } 1.5-3.0] \\
7.5(2.5-12.5)[\text { IQR } 6.0-10.0]\end{array}$ & $p 0.0001$ \\
\hline \multicolumn{3}{|c|}{ Total sleep time (hours) } \\
\hline $\begin{array}{l}\text { Pre-lockdown } \\
\text { During lockdown }\end{array}$ & $\begin{array}{l}9.0(7.0-11.0)[\text { IQR } 8.0-9.5] \\
8.5(6.5-9.0)[\text { IQR } 7.5-9.0]\end{array}$ & $p 0.140$ \\
\hline Seizure latency & $5(0-10.0)[$ IQR $2.0-8.0]$ & \\
\hline
\end{tabular}

Categorical variables are expressed as a number and percentage. Continuous non-parametric variables are reported as the median, range and interquartile [IQR]. Wilcoxon test was used to compare the hours of DST and TST pre and during lockdown period.
0.065, [OR 1.739 (CI 95\% 0.966-3.132)] or the number of used devices $p=0.612$, OR 1.467 [CI 95\% 0.335-6.430] was found. If the analysis was performed in the two separate groups, the results were confirmed as not significant.

\section{Discussion}

During the Covid-19 pandemic, there has been a clinical epidemiological change about the onset of many diseases: in some countries, a decrease of common paediatric diseases has been reported $[2,13]$, such as asthma and acute respiratory tract infection [14]. Since schools and sport centres closed, the number of acute infections and traumas among children were lower than usual [15]. In addition, the literature reports an increase in sleep disorders, depression and other psychiatric disorders in children, during pandemic [16-19]. Moreover, strong social restrictions allowed children to assume incorrect habits about food, physical activities or screen time [20, 21]. Children, indeed, spent a lot of time at home using MMDs such as TV, smartphones, tablets and video consoles [22]. We showed an increase in the numbers of seizures detected in a paediatric Southern Italian cohort during "quarantine/social limitations" (9th March-4th May 2020), compared with the same population during the same months in 2019. These findings confirm the view that the change in life habits, including the use of mobile devices and sleep changes, might have favoured the occurrence of epileptic seizures in a population of children during the 2020 lockdown.

We witnessed a drastic decrease in admissions in ED in Italy [3] and in Santobono-Pausilipon Children's Hospital. Also, we reported a significant increase of accesses for seizures during lockdown period.

Normally, the incidence of epilepsy in children ranges from 41 to $187 / 100000$. A higher incidence is reported from underdeveloped countries. The prevalence is consistently higher than incidence and ranges from 3.2 to 5.5/1000 in developed countries and 3.6-44/1000 in undeveloped countries [23-25]. In our study, we analysed the incidence and prevalence of seizures during Italian lockdown for Covid-19 (9th March to 4th May 2020) comparing to the incidence and prevalence of seizures in the same period of last year. We described a significant increase of seizure prevalence and incidence compared with the same period of the last year: the prevalence of seizures in children accessed to the emergency department of Santobono-Pausilipon Hospital in Naples during the lockdown (9th March-4th May 2020) was 2.6\%, while in the same period of 2019, the prevalence was $0.4 \%$, whilst the incidence was 0.94 and $0.13 \%$, respectively, with statistically significant differences in both cases.

These data could reflect a change in the sanitary organization of assistance (reduction of ambulatory activities and migration of patients to the ED access). In our opinion, however, 
discontinuing of outpatient activities was not very significant. A telemedicine service was created for management and follow-up of known patients, whilst the ambulatory continued to be open for urgency. Most of the patients who benefited from telemedicine were epileptic patients for monitoring and therapeutic modifications. Furthermore, seizures are a reason for access to the emergency department also for the strong emotional impact on parents.

We suspected that some of the conditions experienced during lockdown might have been facilitating factors or triggers for the seizures. In particular, in our study children presented a statistically significant difference in DST and in TST compared with the period before lockdown. In detail, we reported an increasing use of MMDs both in all population and in patients with new-onset seizures or not. We reported, as expected, that older children used devices more than the younger ones. Additionally, considering patients with FE and GE, children that spent more hours using a device, had shorter seizure latency. Precisely, eleven of 45 patients contacted by phone experienced a seizure during device's use. Furthermore, no gender difference has been described.

It is known that seizures are usually unpredictable and arise spontaneously. Regardless, some perturbations like intercurrent diseases sleep disturbances or emotional stress act as a trigger [26]. In literature seizures (e.g. reflex epilepsy) modulated or precipitated by extrinsic (i.e. light, music) or intrinsic (i.e. movements, emotion, cognitive processes) stimuli are described [26, 27]. In susceptible children, seizures triggered by this type of stimuli or processes can have different latencies [28].

Some studies reported that FE is more frequently related to alterations in the sleep-wake rhythm [29] and GE are frequently triggered by external stimuli [30]. In our study, we noticed no difference in terms of presentation of the seizures between focal and generalized, and no predictive factors (number of hours of sleep and device usage, number of devices used) have been found for FE or GE diagnosis.

In our population, only 2 patients $(3.5 \%)$ had photosensitivity. In literature, flashing lights are the most frequent extrinsic trigger in reflex epilepsy and occur in $2 \%$ of epileptic patients, mainly in adolescents and females. In fact, agedependent correlation is described [26].

We emphasize that the maximum age to access to our hospital is 14 years. For this reason, data about photosensitivity could be poor. However, reported rate was in line with the literature.

Some authors deny that increased use of MMDs, in particular video games, is related to a higher risk of seizures in nonphotosensitive patients. Nevertheless, their studies described adults and only "out-of-date" video games [31-33]. It is known the risk of paroxysmal EEG discharges and consequently of clinical epileptic manifestations for the shortness of the distance between subject and TV screen [33], but we did not investigate it.

Of course, we cannot confirm or not a correlation between seizures and mobile media devices (we have not a control population) but only describe a phenomenon observed during Italian lockdown, in our centre. In our opinion, social restrictions, increased use of devices, sleep deprivation, poor sleep quality and also emotional stress could have been facilitating factors or triggers for seizures. We suggest re-evaluating, with further studies, the role of devices and new games as triggers or facilitating factors of seizures.

As in our population, there was a good compliance to the antiepileptic treatment, and the reported increase of seizures is probably due to a lifestyle variation, with a decrease of sleep time and an increase of device use.

Recently, a noticeable increase in the use of devices, especially in older children, was reported $[11,31]$. As announced by American Academy of Pediatrics [34], it is necessary to regulate the use of MMDs, according to the age of the child. It is known, in fact, that overuse of digital media and screens may place children or teenager at risk of obesity, sleep problems, gaming disorder, cyberbullying and risky behaviours (substance abuse, sexual behaviours). In literature the effects of sleep on epileptic seizures are described extensively [35-39]; on the contrary, studies regarding the effects of MMDs on seizures are poor. Probably, seizures might be a possible risk, but future studies are desirable to correlate MMD use with seizures and to understand any pathophysiological mechanisms of them.

Major limitations of the present study are its observational and retrospective design and the lack of a control population to correlate the critical event with the use of devices and the alteration of sleep hours. Moreover, we used only an anamnestic questionnaire, administered via telephone, and the increased number of ED accesses for seizures could reflect the closure of ambulatory facilities in the same period. Finally, we did compare only the same periods of the years 2019 2020, whereas it would have been interesting and more significant to also compare the previous years (at least 5) and to study the trend of accesses during the period pre- and postlockdown.

\section{Conclusions}

The Covid-19 crisis has imposed numerous social restrictions. Since the pandemic was announced, there has been a high drop of accesses to basic services. Regular playgrounds, social group activities, sports clubs and school have been closed. Social relations have been strongly limited to closest family members. This could harm children and adolescent and change habits and behaviours. In our study we reported an increase of seizures, probably precipitated by higher usage 
of devices, a reduction in sleep time and impaired sleep quality. Further studies are needed to better characterize the underlying pathophysiological mechanism and the causal link between seizures and devices overuse and sleep disturbances. Moreover, most of the studies are not recent. Maybe, new lifestyles, simultaneous or continuous use of several devices and new games (sometimes violent and stressful) could be considered. Furthermore, recommendations for families and healthcare providers on the use of mobile media by children are strongly needed.

Acknowledgements Open access funding provided by Università degli Studi della Campania Luigi Vanvitelli within the CRUI-CARE Agreement.

\section{Compliance with ethical standards}

Conflict of interest The authors declare that they have no conflict of interest.

Ethics approval The study was performed in accordance with the principles of Helsinki Declaration.

Consent to participate An informed consent was obtained from all individual participants included in the study. Verbal informed consent was obtained prior to the questionnaire.

Open Access This article is licensed under a Creative Commons Attribution 4.0 International License, which permits use, sharing, adaptation, distribution and reproduction in any medium or format, as long as you give appropriate credit to the original author(s) and the source, provide a link to the Creative Commons licence, and indicate if changes were made. The images or other third party material in this article are included in the article's Creative Commons licence, unless indicated otherwise in a credit line to the material. If material is not included in the article's Creative Commons licence and your intended use is not permitted by statutory regulation or exceeds the permitted use, you will need to obtain permission directly from the copyright holder. To view a copy of this licence, visit http://creativecommons.org/licenses/by/4.0/.

\section{References}

1. Andersen KG, Ramabaut A, Lipkin WI et al (2020) The proximal origin of SARS-CoV-2. Nat Med 26:450-452

2. Isba R, Edge R, Jenner R, Broughton E, Francis N, Butler J (2020) Where have all the children gone? Decreases in paediatric emergency department attendances at the start of the COVID-19 pandemic of 2020. Arch Dis Child 105(7):704-70704. https://doi.org/ 10.1136/archdischild-2020-319385

3. Scaramuzza A, Tagliaferri F, Bonetti L, Soliani M, Morotti F, Bellone S, Cavalli C, Rabbone I (2020) Changing admission patterns in paediatric emergency departments during the COVID-19 pandemic. Arch Dis Child 105(7):704-706. https://doi.org/10. 1136/archdischild-2020-319397

4. Livingston E, Bucher K (2020) Coronavirus disease 2019 (COVID19) in Italy. JAMA 323(14):1335-1335

5. Ludvigsson JE (2020) Systematic review of COVID-19 in children shows milder cases and a better prognosis than adults. Acta Paediatr 109(6):1088-1095
6. Lazzerini M, Barbi E, Apicella A, Marchetti F, Cardinale F, Trobia $G$ (2020) Delayed access or provision of care in Italy resulting from fear of COVID-19. Lancet Child Adolesc Health 4(5):e10-e11

7. Xie X, Xue Q, Zhou Y, Zhu K, Liu Q, Zhang J, Song R (2020) Mental health status among children in home confinement during the coronavirus disease 2019 outbreak in Hubei Province, China. JAMA Pediatr 24:e201619. https://doi.org/10.1001/jamapediatrics. 2020.1619

8. Becker SP, Gregory AM (2020) Editorial Perspective: Perils and promise for child and adolescent sleep and associated psychopathology during the COVID-19 pandemic. J Child Psychol Psychiatry 31. https://doi.org/10.1111/jcpp. 13278

9. Bruni O, Ottaviano S, Guidetti V et al (1996) The sleep disturbance scale for children (SDSC) construct ion and validation of an instrument to evaluate sleep disturbances in childhood and adolescence. $\mathrm{J}$ Sleep Res 5(4):251-261. https://doi.org/10.1111/j.1365-2869. 1996.00251.x

10. Vizcaino M, Buman M, DesRoches CT et al (2019) Reliability of a new measure to assess modern screen time in adults. BMC Public Health 19(1):1-8

11. Kabali HK, Irigoyen MM, Nunez-Davis R et al (2015) Exposure and use of mobile media devices by young children. Pediatrics 136(6):1044-1050

12. Fisher RS (2017) The new classification of seizures by the International League Against Epilepsy 2017. Curr Neurol Neurosci Rep 17(6):48

13. Cozzi G, Zanchi C, Giangreco M, Rabach I, Calligaris L, Giorgi R, Conte M, Moressa V, Delise A, Poropat F (2020) The impact of the COVID-19 lockdown in Italy on a pediatric emergency setting. Acta Paediatr 29:2157-2159. https://doi.org/10.1111/apa.15454

14. Krivec U, Seliger AK, Tursic J (2020) COVID-19 lockdown dropped the rate of paediatric asthma admissions. Arch Dis Child 105:809-810. https://doi.org/10.1136/archdischild-2020-319522

15. Hernigou J, Morel X, Callewier A et al (2020) Staying home during "COVID-19" decreased fractures, but trauma did not quarantine in one hundred and twelve adults and twenty eight children and the "tsunami of recommendations" could not lockdown twelve elective operations. Int Orthop 1. https://doi.org/10.1007/s00264-02004619-5

16. Saurabh K, Ranjan S (2020) Compliance and psychological impact of quarantine in children and adolescents due to Covid-19 pandemic. Indian J Pediatr 1. https://doi.org/10.1007/s12098-020-03347-3

17. Zhou SJ, Wang LL, Yang R, Yang XJ, Zhang LG, Guo ZC, Chen JC, Wang JQ, Chen JX (2020) Sleep problems among Chinese adolescents and young adults during the coronavirus-2019 pandemic. Sleep Med 74:39-47

18. Dellagiulia A, Lionetti F, Fasolo M, Verderame C, Sperati A, Alessandri G (2020) Early impact of COVID-19 lockdown on children's sleep: a four-week longitudinal study. J Clin Sleep Med 16: 1639-1640. https://doi.org/10.5664/jcsm. 8648

19. Innocenti P, Puzella A, Mogavero MP, Bruni O, Ferri R (2020) Letter to editor: CoVID-19 pandemic and sleep disorders-a web survey in Italy. Neurol Sci 41(8):2021-2022. https://doi.org/10. 1007/s10072-020-04523-1

20. Margaritis I, Houdart S, El Ouadrhiri Y et al (2020) How to deal with COVID-19 epidemic-related lockdown physical inactivity and sedentary increase in youth? Adaptation of Anses' benchmarks. Arch Public Health 78:1-6

21. Pietrobelli A, Pecoraro L, Ferruzzi A, Heo M, Faith M, Zoller T, Antoniazzi F, Piacentini G, Fearnbach SN, Heymsfield SB (2020) Effects of COVID-19 lockdown on lifestyle behaviors in children with obesity living in Verona, Italy: a longitudinal study. Obesity 28:1382-1385. https://doi.org/10.1002/oby.22861

22. Nagata JM, Abdel Magid HS, Gabriel KP (2020) Screen time for children and adolescents during the COVID-19 pandemic. Obesity 28:1582-1583. https://doi.org/10.1002/oby.22917 
23. Camfield P, Camfield C (2020) Incidence, prevalence and aetiology of seizures and epilepsy in children. Epileptic Disord 17(2):117123

24. Aaberg KM, Gunnes N, Bakken IJ, Lund Søraas C, Berntsen A, Magnus P, Lossius MI, Stoltenberg C, Chin R, Surén P (2017) Incidence and prevalence of childhood epilepsy: a nationwide cohort study. Pediatrics 139(5):e20163908

25. Fiest KM, Sauro KM, Wiebe S, Patten SB, Kwon CS, Dykeman J, Pringsheim T, Lorenzetti DL, Jetté N (2017) Prevalence and incidence of epilepsy: a systematic review and meta-analysis of international studies. Neurology 88(3):296-303

26. IrmenF WT, Lemieux L (2015) Do reflex seizures and spontaneous seizures form a continuum?-Triggering factors and possible common mechanisms. Seizure 25:72-79

27. Striano S, Coppola A, Del Gaudio L et al (2012) Reflex seizures and reflex epilepsies: old models for understanding mechanisms of epileptogenesis. Epilepsy Res 100(1-2):1-11

28. Koeppe MJ, Caciagli L, Pressler RM et al (2016) Reflex seizures, traits, and epilepsies: from physiology to pathology. Lancet Neurol 115(1):92-105

29. Lanigar S, Bandyopadhyay S (2017) Sleep and epilepsy: a complex interplay. Mo Med 114(6):453-457

30. Wolf P, Beniczky S (2014) Understanding ictogenesis in generalized epilepsies. Expert Rev Neurother 14(7):787-798

31. Paudel S, Jancey J, Subedi N, Leavy J (2017) Correlates of mobile screen media use among children aged 0-8: a systematic review. BMJ Open 7(10):e014585
32. Badinand-Hubert N, Bureau M, Hirsch E, Masnou P, Nahum L, Parain D, Naquet R (1998) Epilepsies and video games: results of a multicentric study. Electroencephalogr Clin Neurophysiol 107(6): $422-427$

33. Bureau M, Hirsch E, Vigevano F (2004) Epilepsy and videogames. Epilepsia 45:24-26

34. American Academy of Pediatrics (2017) American academy of pediatrics announces new recommendations for children's media use USA. https://www.aap.org/en-us/about-the-aap/aappressroom/pages/american-academy-of-pediatrics-announcesnewrecommendations-for-childrens-media-use.aspx

35. Bazil CW (2017, August) Sleep and epilepsy. Semin Neurol 37(4): 407-412. https://doi.org/10.1055/s-0037-1604352

36. Chokroverty S, Nobili L (2017) Sleep and epilepsy. In: Sleep disorders medicine. Springer, New York, pp 915-961

37. Wang YQ, Zhang MQ, Li R et al (2018) The mutual interaction between sleep and epilepsy on the neurobiological basis and therapy. Curr Neuropharmacol 116(1):5-16

38. Frauscher B, Gotman J (2019) Sleep, oscillations, interictal discharges, and seizures in human focal epilepsy. Neurobiol Dis 127: 545-553

39. Kataria L, Vaughn BV (2016) Sleep and Epilepsy. Sleep Med Clin 11(1):25-38

Publisher's note Springer Nature remains neutral with regard to jurisdictional claims in published maps and institutional affiliations. 